\title{
Lieber Genosse K.[arl] V.[ölker]
}

Vollig überraschend, doch darum nicht minder willkommen traf heute Dein Lebensmittelpaket hier ein. Ich sage Dir und allen denen, die mit dazu beigetragen haben, uns diese schöne Maifreude zu bereiten, meinen herzlichen Dank. Bei unserer Ernährungslage ist ein solches Paket von unermeßlichem Wert. Von unserem Standpunkt aus, ist es ja ein trauriges Zeichen, daß so viele Menschen Not leiden müssen, wo es bei ein wenig Vernunft möglich wäre, alle Menschen auf der Erde gut zu ernähren. Aber trotz aller Not, sind es nicht die Lebensmittel allein, wofür ich Dir dankbar bin, sondern das Gefühl, es gibt noch jemand, der sich um dich kümmert, der an dich denkt, du stehst nicht ganz allein, erfüllt uns mit freudiger Dankbarkeit und reißt uns wieder hoch, gibt uns neue Kraft zur weiteren Arbeit, wenn wir im täglichen Kleinkampf zu ermüden drohen. Weißt Du, als wir 33 in die Illegalität gingen, wußten wir, daß es nicht ohne Opfer abgehen würde, wenn auch die Wirklichkeit schlimmer aussah, als wir es voraus geahnt hatten. Aber das was nach 45, nach dem Zusammenbruch des 1000jährigen Reiches geschah, hatten wir uns doch ein wenig anders vorgestellt. Wir sind nicht in die Illegalität gegangen, um Vorteile zu erwarten. Daß es Opfer zu bringen galt, wußten wir im Voraus. Es haben auch die Opfer bringen müssen, die nicht direkt im Netz der Gestapo hängen blieben. Die Bomben der Alliierten machten keinen Unterschied zwischen Faschisten und Antifaschisten. Doch darüber wollen wir nichts sagen, auch nicht darüber, daß wir Illegalen genau so Reparationen und Kriegsschulden bezahlen müssen, wie die Nazis, denn auch die von den Nazis Überfallenen haben dasselbe zu tragen. Was aber für uns Illegale bitter war, war die Einstellung vieler sozialistischer Genossen aus dem Auslande, die uns mit den Nazis auf eine Stufe stellten - Es war uns jedesmal ein Schlag ins Gesicht, wenn wir hören mußten, die Aufnahme in die sozialistische Internationale oder in den Weltgewerkschaftsbund wurde abgelehnt ${ }^{1}$. Die deutsche Widerstandsbewegung hat länger und nicht weniger hart unter dem nazistischen Druck gestanden, als die der überfallenen Länder. Nur glaube ich, unser Kampf war insofern schwerer und weniger erfolgreich, weil wir bei unsern Landsleuten zu we-

\footnotetext{
' Von den unmittelbar nach Kriegsende einsetzenden Bemühungen um einen Wiederaufbau der Sozialistischen Arbeiter-Internationale blieb die SPD zunächst ausgeschlossen; 1946 wurde die Zulassung deutscher Delegierter zweimal abgelehnt. Erst zur Internationalen Sozialistischen Konferenz vom 6.-9.6. 1947 in Zürich wurden drei Vertreter der SPD zur Beantwortung von Fragen und zur Darlegung ihrer Position eingeladen; die für eine Aufnahme der SPD notwendige Zweidrittelmehrheit kam noch nicht zustande. Erst die Internationale Sozialistische Konferenz in Antwerpen beschloß am 1. 12. 1947 mit $12: 4: 2$ Stimmen die Wiederaufnahme der SPD in die Internationale.

Der im Oktober 1945 gegründete Weltgewerkschaftsbund (WGB) machte im Juli 1947 die Bildung eines gesamtdeutschen Gewerkschaftsbundes, der alle Länder und Zonen umfaßte, zur Voraussetzung für einen deutschen Beitritt; ein solcher Zusammenschluß kam nicht zustande. Der WGB wurde zunehmend von den kommunistischen Organisationen beherrscht; dem als Gegenorganisation Ende 1949 gegründeten Internationalen Bund Freier Gewerkschaften (IBFG) gehörte der im Oktober 1949 gebildete DGB von Anfang an als Mitglied an.
} 
nig Unterstützung aber zuviel Feinde fanden. In vielen Fällen ging der Kampf sogar bis in die eigene Familie hinein - während die Widerstandskämpfer in den unterdrückten Ländern bei der Mehrzahl ihrer Landsleute Unterstützung fanden, unbeschadet dessen, daß die Grundmotive, aus denen heraus der Kampf geführt wurde, sich bei den verschiedenen Gruppen diametral gegenüberstanden. Die Einstellung unserer ausländischen Genossen hat sich ja in der letzten Zeit erfreulicher Weise geändert. Und wir hoffen und wünschen, daß sich die Bindungen der Sozialisten aller Länder noch enger gestalten werden. Denn es darf keine nationalen Sozialisten geben, wenn unser Kampf um den Sozialismus mit Erfolg gekrönt sein soll. Wir sehen, wie sich der Kapitalismus aus der nationalen Eingeengtheit zu lösen versucht. Gleich ob es sich um den Privatkapitalismus westlicher oder um den Staatskapitalismus östlicher Prägung handelt. (Paneuropabewegung, Pansozialismus, Marshallplan usw.) Für uns heißt die Entscheidung nicht Ost oder West, sondern wir haben uns für den dritten Weg, der Schaffung der Vereinigten sozialistischen Staaten auf föderalistischer Grundlage zu entscheiden. Das bedeutet aber für uns, daß wir die internationale Zusammenarbeit aller Sozialisten enger gestalten müssen als bisher. Wäre unsere internationale Zusammenarbeit eine bessere gewesen, hätten die letzten Jahrzehnte der Weltgeschichte aller Wahrscheinlichkeit nach einen anderen Verlauf genommen.

Lieber Karl, Du stehst gewissermaßen auf Vorposten. Deine Lebensmittelpaketsendungen beweisen uns, daß Du uns in der Emigration nicht vergessen hast, und das freut uns und erfüllt uns mit Stolz. Doch in dem Liebesgabendienst darf sich Deine Aufgabe nicht erschöpfen, denn Du bist einer der Brückenbauer der internationalen Verständigung - Und nur auf dem Wege der internationalen Verständigung, des Erfahrungsaustausches und gemeinsamer Zielführung können wir unsern Kampf um die sozialistische Weltordnung mit Erfolg führen.

Lieber Karl, da ich annehme, daß Dich vielleicht einiges hier aus Wesel interessiert, so teile ich Dir folgendes mit.

Daß Bernhard Schmitz im Herbst 33 einem Herzschlag erlegen ist, wird Dir ja wohl bekannt sein. Rudi Jacobi verunglückte I 940 tötlich, als er auf einen fahrenden Zug aufsteigen wollte. Wilhelm Kirking, der auch erst nach Holland und von da aus ins Saargebiet emigrierte, nach der Saarabstimmung zurückkam und nach Verbüßung seiner $1 / 2$ jährigen KZ-haft von seiner Familie nicht wieder aufgenommen wurde, starb 39 in Bielefeld, wo er Arbeit gefunden hatte. Stacho Matuszeck starb 38 an Magenkrebs. Von Dr. Tono Rump, die 33 nach Ungarn emigrierte, fehlt seit 36 jede Nachricht. Mein Vater starb im Juni 45 in der russisch-besetzten Zone an hochgradiger Abmagerung, Herzschwäche und Dickdarmkatarrh. Ich selbst bin seit etwa Io Jahren an meinen Stuhl gefesselt, da meine Beine infolge einer vermurksten Gelenkentzündung versteift sind. Heini Landsiedel ist im Januar bevorzugt, wegen seiner politischen Tätigkeit, aus der franz. Kriegsgefangenschaft entlassen worden. Wie Du siehst, haben wir mit unsern alten Funktionären Pech gehabt. Heini Landsiedel und ich sind die einzigen hier am Ort noch lebenden Vorstandsmitglieder der SAP. Da ich infolge Mangels eines Fahrstuhles mich nicht nach außen betätigen kann, steht Heini in den Versammlungen immer so ziemlich allein. Aber er kommt mich immer treu besuchen und so haben wir doch Gelegenheit, uns über alles gründlich auszusprechen. So bin ich doch trotz allem immer noch mitten drin. Wir sind und bleiben immer noch die Alten Und wir hoffen, daß dadurch, daß Heini wieder hier ist, unser Einfluß mit der Zeit wächst, denn in die Partei sind viele Neusozialisten eingetreten, und wir Alten müssen scharf aufpassen, daß diese nicht einen unheilvollen Einfluß in der Bewegung ausüben. 
Die Neusozialisten haben viel Schulung nötig. Leider ist das Schulungsmaterial hier sehr knapp. Und für die mündliche Bearbeitung fehlt es uns an Leuten. Die Verluste unter unseren Funktionären waren sehr groß.

Lieber Karl, ich will jetzt schließen. Nochmals herzlichen Dank. Es grüen Dich und Deine holländischen Genossen zum I. Mai mit sozialistischem Gruß

August Aßmus

$[\ldots]^{2}$

u. Heini Landsiedel.

${ }^{2}$ Kurze Nachbemerkung von Karl Völker an Joseph Lang, in der es u.a. heißt: "Wie Du aus dem Briefe ersehen kannst, fehlt unserm Freunde ein Fahrstuhl, wenn es Euch möglich sein sollte hierfür etwas Geld locker zu machen, so wäre das sehr gut." In einem Postskriptum zu einem Brief an Joseph und Erna Lang vom I1.6. 1948 schreibt Karl Völker: „August Aßmus erhält einen Fahrstuhl aus der Schweiz."

Der Brief von August Aßmus liegt nur in einer von Karl Volker zeitgleich angefertigten Abschrift vor, die er an Joseph und Erna Lang sandre. 